\title{
AXIAL SPEED OF SOUND FOR THE MONITORING OF INJURED EQUINE TENDONS: A PRELIMINARY STUDY
}

\author{
Claudio Vergari ${ }^{\mathrm{a}, \mathrm{b}, *}$, Philippe Pourcelot ${ }^{\mathrm{a}, \mathrm{b}}$, Bérangère Ravary-Plumioën ${ }^{\mathrm{a}, \mathrm{b}}$, Anne-Gaëlle Dupays ${ }^{\mathrm{a}, \mathrm{b}}$, \\ Sandrine Jacquet ${ }^{\mathrm{a}, \mathrm{b}}$, Fabrice Audigié ${ }^{\mathrm{a}, \mathrm{b}}$, Jean-Marie Denoix ${ }^{\mathrm{a}, \mathrm{b}}$, Pascal Laugier ${ }^{\mathrm{c}}$, \\ David Mitton $^{\mathrm{d}}$ and Nathalie Crevier-Denoix ${ }^{\mathrm{a}, \mathrm{b}}$
}

\begin{abstract}
Equine superficial digital flexor tendons (SDFT) are often injured, and they represent an excellent model for human sport tendinopathies. While lesions can be precisely diagnosed by clinical evaluation and ultrasonography, a prognosis is often difficult to establish; the knowledge of the injured tendon's mechanical properties would help anticipating the outcome.

The objectives of the present study were to compare the axial speed of sound (SOS) measured in vivo in normal and injured tendons and to investigate their relationship with the tendons' mechanical parameters, in order to assess the potential of quantitative axial ultrasound to monitor the healing of injured tendons.

SOS was measured in vivo in the right fore SDFTs of 12 horses during walk, before and 3.5 months after the surgical induction of a bilateral core lesion. The 12 horses were then euthanized, their SDFTs isolated and tested in tension to measure their elastic modulus and maximal load (and corresponding stress). SOS significantly decreased from $2179.4 \pm 31.4 \mathrm{~m} / \mathrm{s}$ in normal tendons to $2065.8 \pm 67.1 \mathrm{~m} / \mathrm{s} 3.5$ months after the surgical induction, and tendons' elastic modulus $(0.90 \pm 0.17 \mathrm{GPa})$ was found lower than what has been reported in normal tendons. While SOS was not correlated to tendon maximal load and corresponding stress, the SOS normalized on its value in normal tendons was correlated to tendons' elastic modulus.
\end{abstract}

These preliminary results confirm the potential of axial SOS in helping the functional assessment of injured tendon.

Keywords: Tendon; Quantitative ultrasound; Speed of sound; Elastic modulus; Mechanical properties.

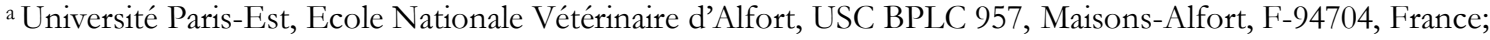
INRA, USC BPLC 957, Maisons-Alfort, F-94704, France.

b UPMC Univ Paris 6, UMR CNRS7623, LIP, Paris, F-75005 France.

c Université de Lyon, F-69622, Lyon, France; IFSTTAR, LBMC, UMR_T9406, F-69675, Bron; Université Lyon 1, Villeurbanne

${ }^{*}$ Corresponding author: c.vergari@gmail.com (C.Vergari)
} 


\section{Introduction}

The superficial digital flexor tendon (SDFT) is one of the most commonly injured tendons in horses (Patterson-Kane and Firth, 2009; Thorpe et al., 2010) and it is considered as an excellent model for human sport tendinopathies. Tendon lesions are usually accompanied by enlargement of the affected area and a decrease in tendon's elastic modulus and maximal stress (CrevierDenoix et al., 1997). The tendon healing response is slow and often inadequate, as indicated by the high recurrence rates of these injuries (Patterson-Kane and Firth, 2009); thus, lesion's evaluation and follow up are important in order to limit the horse's intervals out of work and avoid recurrent injuries.

Ultrasonography is widely used to evaluate tendon lesion severity and progression (Marr et al., 1993; Rantanen et al., 1985). While this technique is considered one of the most accurate diagnostic tools in early stage, advanced healing lesions tend to present normal echogenicity (Denoix et al., 1990) although the tendon has not yet completely recovered. In particular, the mechanical properties of tendon play a determinant role in its ability to resume work but a robust means to non-invasively assess those properties is still lacking; however, it is possible to estimate them by quantitative analysis of ultrasonographic images (CrevierDenoix et al., 2005). More recently, a technique based on in-vivo kinetic and kinematic analysis has been proposed to characterize the limb's stiffness of horses with healing tendons (Dakin et al., 2011),

Quantitative axial ultrasound in tendon represents a relatively new field of study, while bone applications are already well spread (Laugier et al., 2008; Moilanen, 2008). Axial speed of sound (SOS) measurements have been applied to evaluate tendon load non-invasively (Crevier-Denoix et al., 2009a; Pourcelot et al., 2005; Roux and Defontaine, 2005), but its potential to quantitatively follow-up tendon lesions has yet to be evaluated.

The objectives of this study were to compare invivo axial SOS measurements in normal and injured tendons and to assess the relation between SOS and tendon mechanical properties, in order to evaluate the potential of quantitative axial ultrasound to monitor the healing of injured tendons.

\section{Materials and methods}

\subsection{Subjects}

The subjects of the present study were 12 French Trotters (2-4 years old, $428 \pm 40 \mathrm{~kg}$ average body mass) who participated in a clinical trial testing a regenerating agent on tendon lesions. The trial required the bilateral surgical induction (SI) of tendon core lesions and the euthanasia of the horses 3.5 months after the SI (as approved by the Ethical Committee of the National Veterinary School of Alfort). Horses were weighed before the SI and before the euthanasia (finding a non-significant variation of $-0.1 \pm 2.5 \%$ ), they had no history of previous tendon injury, and their SDFTs were sound upon inspection, palpation and ultrasonographic examination prior to entry to the study.

The lesions were induced with a specially designed amagnetic pin, $30 \mathrm{~cm}$ long and ending with a 4 edged arrowhead (Denoix et al., personal communication), with a surgical technique similar to the one described by Schramme et al. (2010). The lesions were targeted in a region of interest (ROI) in the mid metacarpal area, a site that is highly susceptible to injuries. Briefly, a channel was made with a trocar through the tendon core under realtime ultrasonographic guidance, in the axial direction, where the arrow-shaped instrument was inserted. The surgeon repeatedly inserted and retracted this tool in the proximodistal direction, in order to tear the tendon fibres. The skin was sutured after the tool removal and non-compressive bandage was applied on the limb. The regenerating agent or saline solution (placebo) was bilaterally injected 3 weeks after the surgery. No lameness was detected 3.5 months after SI. 


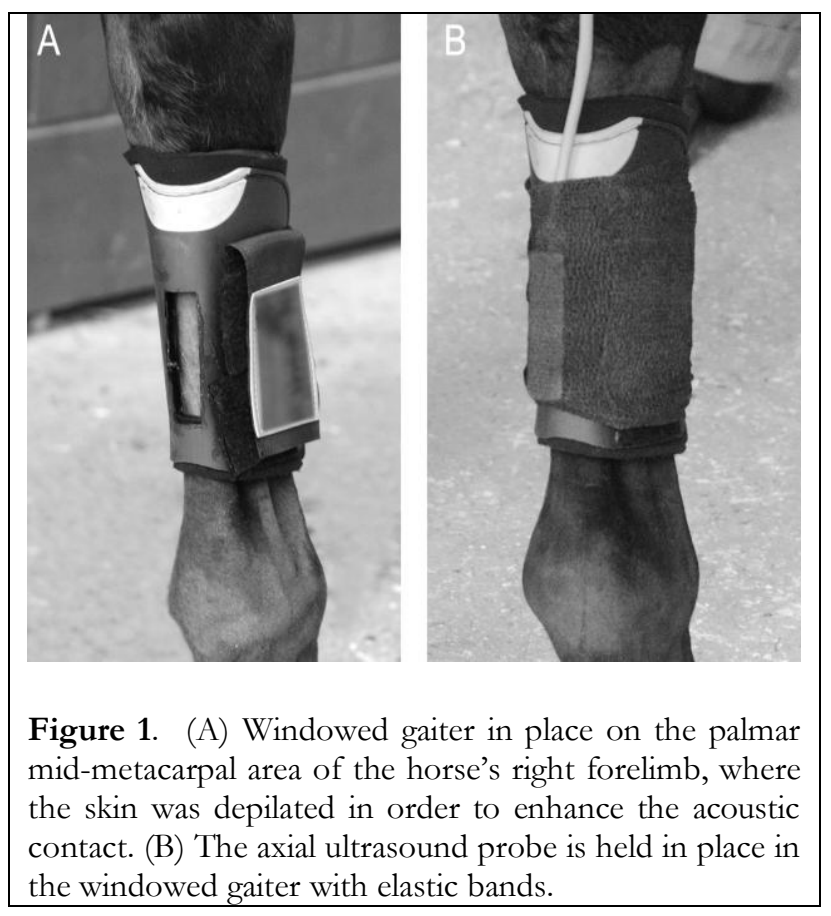

\subsection{Speed of sound}

SOS in the right SDFT of each horse was measured with an ultrasonic axial measurement device similar to the one previously described by Pourcelot et al. (2005). This probe is composed by one emitter $(1 \mathrm{MHz}$ broadband pulses) and two receivers; a windowed gaiter (Fig. 1) allowed the positioning of the probe on the ROI (in the palmar metacarpal area) while elastic bands held it in place. Axial SOS was measured from the time of flight of the first arriving signal (FAS) between the two receivers. The FAS was detected with the first zerocrossing criterion (Bossy et al., 2002). This probe explores a tendon region of about $1 \mathrm{~cm}$ in the axial direction (equal to the distance separating the receivers).

SOS in normal $\left(\mathrm{SOS}_{\mathrm{N}}\right.$, before $\left.\mathrm{SI}\right)$ and injured tendon $\left(\mathrm{SOS}_{\mathrm{I}}, 3.5\right.$ months after $\left.\mathrm{SI}\right)$ was assessed averaging the maximal SOS, corresponding to the maximal SDFT load (Pourcelot et al., 2005), measured in each stride during 6 series of walk on an asphalt pavement; $\mathrm{SOS}_{\mathrm{N}}$ and $\mathrm{SOS}_{\mathrm{I}}$ were both determined by averaging about 30 strides for each horse. The horse's speed was not controlled; however the horses were always led by the same handler who maintained a constant speed.
The expected wavelength in the SDFT with the adopted ultrasound configuration $(\lambda=$ SOS $/$ frequency $\approx 2 \mathrm{~mm}$ ) is smaller than the average tendon dorsopalmar thickness in the metacarpal region $(\sim 5 \mathrm{~mm}$ in normal tendons, Vergari et al., 2010). Therefore, it can reasonably be assumed that the measured SOS corresponds to that of a bulk compression wave propagating in the tendon (Bossy et al., 2002), giving (Rose, 2004):

$$
\mathrm{SOS}=\sqrt{\mathrm{C}_{11} / \rho} \quad \text { Eq. } 1
$$

where $C_{11}$ is the tendon's axial stiffness coefficient and $\varrho$ is tendon's mass density.

The stiffness coefficient $C_{11}$ is proportional to tendon's Young's modulus and it is a function of its Poisson's ratio. Poisson's ratio has been measured in the SDFT and it was found constant with strain and near the limit of incompressibility (Vergari et al., 2011); this implies that tendon's volume does not significantly vary during loading. Thus, given that tendon's mass losses are negligible during axial strain, mass density should also be constant.

It was thus assumed that SOS variations at walk are proportional to the square root of tendon's Young's modulus, which is load-dependent (Riemersma and Schamhardt, 1985). However, $\mathrm{SOS}_{\mathrm{N}}$ and $\mathrm{SOS}_{\mathrm{I}}$ were defined as the average peak values during walk, so their difference should not depend on tendon load since neither lameness nor weight change were detected at 3.5 months from SI.

\subsection{Mechanical properties}

The 12 horses were euthanized after the measurement of $\mathrm{SOS}_{\mathrm{I}}$; each right forelimb SDFT was isolated between 1 and 7 hours after death (the entire limbs were preserved in plastic bags at $4^{\circ} \mathrm{C}$ during this time) leaving intact the tendon distal insertion on the middle phalanx. Tendons were tested in tension immediately after isolation and according to the protocol described by Crevier-Denoix et al. (2005), at a constant speed of $60 \mathrm{~mm} / \mathrm{min}$ (corresponding to $11.7 \pm 2.4 \%$ axial strain $/ \mathrm{min}$ ). Each tendon was installed in the testing machine (Insight 30, MTS Systems Corporation, Eden Prairie, MN USA, $100 \mathrm{~Hz}$ sampling rate) by blocking the 
phalanx with metal rods and the proximal end in a cryo-jaw (Riemersma and Schamhardt, 1982). Two needles were transversely inserted in the tendon, delimiting a region centred where SOS was measured in vivo, and they were equipped with reflecting scotchlight markers on both ends. Those markers were then filmed with a high definition camera (Casio Exilim EX-F1) during the mechanical test and tracked with a custom made software. The instantaneous length $(\mathrm{L})$ of this region was defined as the distance between the middle points of each pair of markers. The segment's initial length $\left(\mathrm{L}_{0}, 3.4\right.$ $\pm 0.4 \mathrm{~cm})$ was measured for a $100 \mathrm{~N}$ pre-load. True strain $(\varepsilon)$ was then calculated as $\varepsilon=\ln \left(\mathrm{L} / \mathrm{L}_{0}\right)$.

Tendons' CSAs were measured by ultrasonography. CSA of normal $\left(\mathrm{CSA}_{\mathrm{N}}\right)$ and injured tendons $\left(\mathrm{CSA}_{\mathrm{I}}\right)$ was measured in vivo, with the horse standing, while CSA of isolated tendons was measured in vitro $\left(\mathrm{CSA}_{\mathrm{E}}\right)$ in water, with the tendon slightly taut. True stress $(\sigma)$ was calculated by assuming that tendon is incompressible (Vergari et al., 2011), as $\sigma=\mathrm{F} \cdot(1+\varepsilon) / \mathrm{CSA}_{\mathrm{E}}$, where $\mathrm{F}$ is the tendon's load and $\varepsilon$ is the axial true strain. Each true stress/strain curve (Fig. 2) was then approximated with a $3^{\text {rd }}$ order polynomial (Crevier et al., 1996); the maximum of the polynomial's first derivative was retained as tendon's instantaneous Young's modulus $\left(\mathrm{E}_{\text {INST }}\right)$, while the derivative's value observed at $7.3 \mathrm{~N} / \mathrm{kg}$ (the expected maximal tendon load at walk normalized on the horse's weight, Harrison et al., 2010) was retained as the Young's modulus likely corresponding to the maximal SOS at walk $\left(\mathrm{E}_{\mathrm{W}}\right)$. Engineering values were also calculated in order to be compared to previous literature data. Engineering stress at maximal load was defined as the ratio $\mathrm{F}_{\mathrm{MAX}} / \mathrm{CSA}_{\mathrm{E}}$, while approximated Young's modulus $\left(E_{A}\right)$ was defined as the maximum of

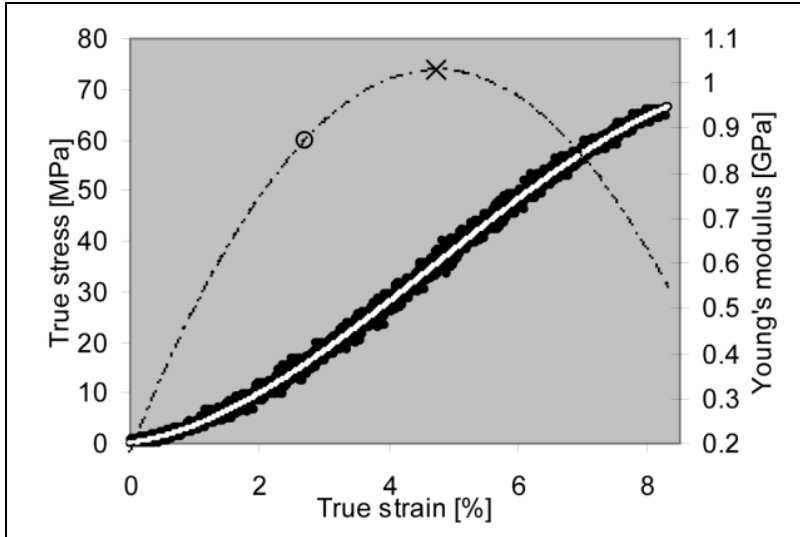

Figure 2. True stress/strain curve of horse \#8 (left ordinates axis). The white line is a 3rd degree polynomial approximating the curve, while the dashed line is the instantaneous Young's modulus (i.e., the polynomial's first derivative, right ordinates axis). The cross and the circle are the maximal instantaneous Young's modulus and the instantaneous Young's modulus expected at walk, respectively.

the derivative of the engineering stress/strain curve, where the engineering strain is $\left(\mathrm{L}_{-} \mathrm{L}_{0}\right) / \mathrm{L}_{0}$.

\subsection{Statistics}

Normality was tested with the Lilliefors test. Pearson's correlation coefficient was calculated for normally distributed variables while Spearman's rank correlation coefficient was used for the non-normally distributed ones. Differences between measurements in normal and injured tendon were statistically analyzed with Wilcoxon signed-rank test for nonnormally distributed data. Significance level was set at $\mathrm{p}<0.05$.

\section{Results}

\subsection{Speed of sound}

Average $\mathrm{SOS}_{\mathrm{N}}$ was $2179.4 \pm 31.4 \mathrm{~m} / \mathrm{s}$ while average $\mathrm{SOS}_{\mathrm{I}}$ was significantly lower $(\mathrm{p}<$ 0.001), at $2065.8 \pm 67.1 \mathrm{~m} / \mathrm{s}$ (Table 1, Fig. 3); 


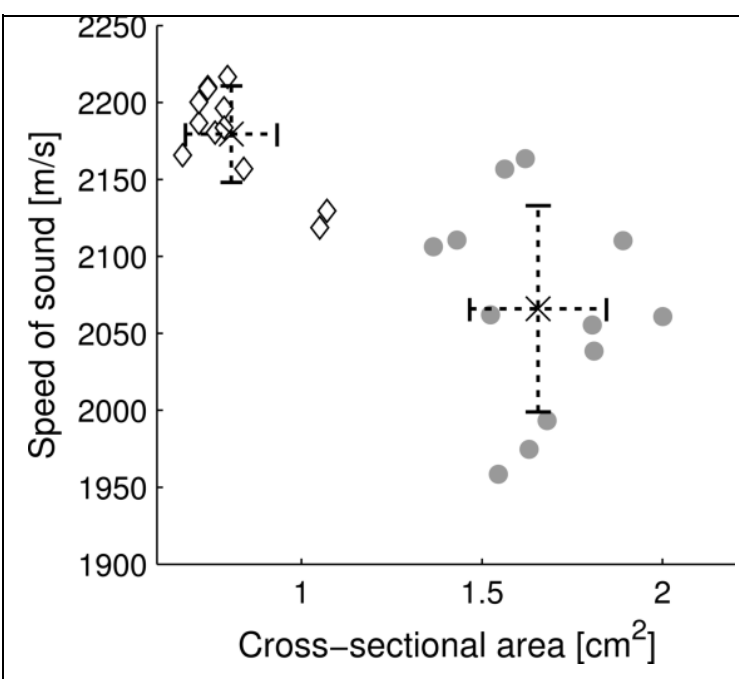

Figure 3. Axial speed of sound (SOS) in 12 superficial digital flexor tendons, before (diamonds) and 3.5 months after (dots) the surgical induction of core lesions, plotted against tendon cross-sectional area (CSA). Mean \pm SD of SOS and CSA (cross and dotted lines) are shown for normal and injured tendons, separately; differences in both SOS and CSA are significant $(p<0.05)$.

SOS was already significantly decreased (2093.2 $\pm 48.8 \mathrm{~m} / \mathrm{s}, \mathrm{p}<0.001) 2$ weeks after the surgical induction. Figure 4 compares the SOS in normal and injured tendon at walk. The SOS measurements revealed highly repeatable, since the short-term precision error, as defined by Gluer et al. (1995), for the determination of $\mathrm{SOS}_{\mathrm{N}}$ and $\mathrm{SOS}_{\mathrm{I}}$ was 0.26 and $0.21 \%$, respectively.

\subsection{Structural and mechanical parameters}

Table 1 reports the results for each tendon while Figure 2 shows an example of true stress/strain curve and instantaneous Young's modulus. Average maximal load was $14.1 \pm 1.1$ $\mathrm{kN}$, corresponding to an average true stress of $80.12 \pm 9.98 \mathrm{MPa}$.

The $3^{\text {rd }}$ order polynomial proved to be a good fit for the true stress/strain data (average RMSE $=1.02 \pm 0.2 \mathrm{MPa}$ ). The derivative of the stress/strain curve for 2 out of 12 tendons (\#9 and \#11) did not present a maximum because those tendons failed either proximally or distally to the lesion site; therefore, $\mathrm{E}_{\mathrm{INST}}$ could not be evaluated for them.

CSA of injured tendons $\left(1.66 \pm 0.19 \mathrm{~cm}^{2}\right)$ was significantly higher $(p<0.001)$ than in normal tendons $\left(0.81 \pm 0.13 \mathrm{~cm}^{2}\right) . \quad \mathrm{CSA}_{\mathrm{E}}$ was significantly higher than $\mathrm{CSA}_{\mathrm{I}}$, but the two were strongly correlated $(\mathrm{r}=0.82, \mathrm{p}=0.001)$.

\subsection{Correlations}

Both $\mathrm{SOS}_{\mathrm{N}}$ and $\mathrm{SOS}_{\mathrm{I}}$ were not correlated to tendons' $\mathrm{E}_{\mathrm{INST}}$, or to their maximal load or corresponding stress. However, a correlation was found between $E_{\text {INST }}$ and the ratio $\operatorname{SOS}_{\mathrm{I}} / \mathrm{SOS}_{\mathrm{N}}(\mathrm{n}=10$, Spearman's $\varrho=0.70, \mathrm{p}=$ 0.025). The correlation was similar when considering the ratio $\mathrm{SOS}_{\mathrm{I}} / \mathrm{SOS}_{\mathrm{N}}$ versus $\mathrm{E}_{\mathrm{A}}(\mathrm{n}=$ 10, Spearman's $\varrho=0.72, \mathrm{p}=0.019)$ or $\mathrm{E}_{\mathrm{W}}$ (Fig.5; $\mathrm{n}=12$, Spearman's $\varrho=0.66, \mathrm{p}=0.022$ ). $\mathrm{SOS}_{\mathrm{I}} / \mathrm{SOS}_{\mathrm{N}}$ was found correlated with $\mathrm{CSA}_{\mathrm{N}}$ (Spearman's $\varrho=0.72, \mathrm{p}=0.008)$, but not with $\mathrm{CSA}_{\mathrm{I}}$.

\section{Discussion}

This is the first time that axial SOS in normal and injured tendons are compared, observing a significant decrease 3.5 months after the induction of a core lesion. SOS was also compared to tendon's mechanical properties, finding a correlation between the normalized SOS $\left(\mathrm{SOS}_{\mathrm{I}} / \mathrm{SOS}_{\mathrm{N}}\right)$, measured in vivo during walk, and the tendons' elastic modulus measured in vitro. The measurements were performed during a clinical trial testing of a regenerative agent, so half of the horses were bilaterally treated with this molecule while the other half was administered a placebo; however, the evaluation of this product was beyond the scope of the present paper.

Axial SOS have previously been measured in vitro in loaded SDFT (Crevier-Denoix et al., 2009b), finding SOS values comparable to those measured in the present study for normal tendons $(2179.4 \pm 31.4 \mathrm{~m} / \mathrm{s})$; the maximal SOS difference observed among those tendons (100 $\mathrm{m} / \mathrm{s}$ at axial load of $1100 \mathrm{~N}$ ) was similar to the present results $(98 \mathrm{~m} / \mathrm{s})$. Injured tendons, on the other hand, present a higher variability $(2065.8 \pm 67.1 \mathrm{~m} / \mathrm{s})$, with a maximal difference among tendons of $205.8 \mathrm{~m} / \mathrm{s}$. This variability probably results from the concurrence of the initial inter-tendon variability, the slight variability in lesions' shape and position within 


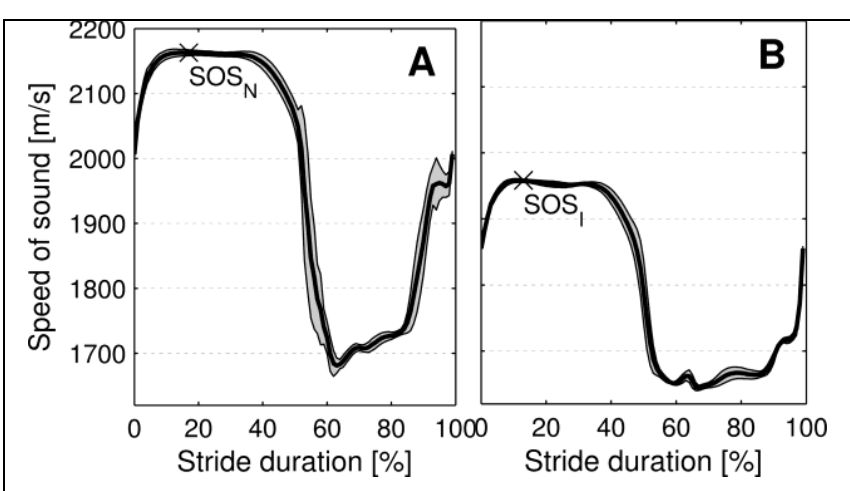

Figure 4. Average axial speed of sound (SOS, mean \pm SD) in the right superficial digital flexor tendon of horse \#8, before (A) and 3.5 months after (B) the surgical induction of a core lesion. Each curve represents the average SOS of 30 strides and is plotted against the stride duration (in percentage), although the beginning of the stride is defined with an arbitrary SOS threshold. SOSN and SOSI are the average maximal SOS in normal and injured tendon, respectively.

the tendon and the additional effects of each lesion's progression; however, the initial lesion's severity was clinically and ultrasonographically assessed by trained clinicians and found to be homogeneous among tendons.

An average SOS decrease of $5 \pm 3 \%$ was observed 3.5 months after the surgical induction, while horse's weight did not significantly vary and no lameness or locomotion alteration was visually detected at that stage by experienced clinicians. Therefore, tendon peak load at walk was likely the same between measurements for a given horse. Besides, in-vitro SOS measurements (CrevierDenoix et al., 2009b) suggest that a decrease of $114 \mathrm{~m} / \mathrm{s}$ (corresponding to the average SOS decrease observed 3.5 months after the induction) would be induced by a decrease of the maximal tendon load at walk of about 3500 $\mathrm{N}$, which is not realistic. Moreover, it was previously demonstrated that SOS measurements in the current configuration are independent of the skin's thickness (Pourcelot et al., 2005); therefore, the difference between $\mathrm{SOS}_{\mathrm{N}}$ and $\mathrm{SOS}_{\mathrm{I}}$ in each horse should only depend on tendon's alterations.

The correlation of normalized SOS with $\mathrm{E}_{\mathrm{W}}$ was similar to the one with $\mathrm{E}_{\mathrm{INST}}$; this confirms that the lack of control of tendon load did not influence much this correlation, although load standardization might improve it. No correlation was found between SOS and tendon's maximal load, although it would have represented valuable information in clinical practice.

Approximated Young's modulus in normal SDFT have been previously observed between

Table 1. Speed of sound (SOS) and cross-sectional area (CSA) of normal and injured tendon (N and I subscripts, respectively), CSA measured in vitro (E subscript), initial length of in-vitro tendon segment $\left(\mathrm{L}_{0}\right)$, instantaneous and approximated tendons Young's modulus ( $\mathrm{E}_{\mathrm{INST}}$ and $\mathrm{E}_{\mathrm{A}}$, respectively), which could not be calculated for horses \#9 and \#11 (X), instantaneous Young's modulus corresponding to the maximal tendon load at walk (Ew), maximal in-vitro load $\left(\mathrm{F}_{\mathrm{MAX}}\right)$ and the corresponding true stress ( $\left.\sigma_{\mathrm{MAX}}\right)$.

\begin{tabular}{lccccccccccc}
\hline & $\begin{array}{l}\mathrm{SOS}_{\mathrm{N}} \\
{[\mathrm{m} / \mathrm{s}]}\end{array}$ & $\begin{array}{c}\mathrm{SOS}_{\mathrm{I}} \\
{[\mathrm{m} / \mathrm{s}]}\end{array}$ & $\begin{array}{c}\mathrm{CSA}_{\mathrm{N}} \\
{\left[\mathrm{cm}^{2}\right]}\end{array}$ & $\begin{array}{c}\mathrm{CSA}_{\mathrm{I}} \\
{\left[\mathrm{cm}^{2}\right]}\end{array}$ & $\begin{array}{c}\mathrm{CSA}_{\mathrm{E}} \\
{\left[\mathrm{cm}^{2}\right]}\end{array}$ & $\begin{array}{c}\mathrm{L}_{0} \\
{[\mathrm{~cm}]}\end{array}$ & $\begin{array}{c}\mathrm{E}_{I N S T} \\
{[\mathrm{GPa}]}\end{array}$ & $\begin{array}{c}\mathrm{E}_{\mathrm{A}} \\
{[\mathrm{GPa}]}\end{array}$ & $\begin{array}{c}\mathrm{E}_{\mathrm{W}} \\
{[\mathrm{GPa}]}\end{array}$ & $\begin{array}{c}\sigma_{\mathrm{MAX}} \\
{[\mathrm{MPa}]}\end{array}$ & $\begin{array}{c}\mathrm{F}_{\mathrm{MAX}} \\
{[\mathrm{kN}]}\end{array}$ \\
\hline 1 & 2129.5 & 2038.5 & 1.07 & 1.81 & 2.01 & 3.9 & 0.97 & 0.84 & 0.84 & 86.99 & 15.31 \\
2 & 2118.7 & 2055.5 & 1.05 & 1.81 & 1.99 & 3.2 & 1.29 & 1.15 & 1.03 & 86.41 & 15.76 \\
3 & 2183.6 & 2106.2 & 0.79 & 1.37 & 1.74 & 3.2 & 0.95 & 0.80 & 0.79 & 91.61 & 13.84 \\
4 & 2209.9 & 2110.2 & 0.74 & 1.89 & 2.30 & 3.5 & 0.96 & 0.77 & 0.67 & 70.13 & 14.52 \\
5 & 2200.1 & 1974.7 & 0.72 & 1.63 & 2.12 & 3.5 & 0.87 & 0.74 & 0.70 & 80.71 & 14.93 \\
6 & 2196.2 & 2156.7 & 0.79 & 1.56 & 2.06 & 2.9 & 1.06 & 0.95 & 0.94 & 66.65 & 12.59 \\
7 & 2186.7 & 1993.4 & 0.72 & 1.68 & 2.01 & 3.1 & 0.78 & 0.67 & 0.58 & 73.63 & 12.88 \\
8 & 2165.8 & 1957.7 & 0.67 & 1.55 & 1.86 & 3.3 & 1.02 & 0.90 & 0.87 & 73.29 & 12.48 \\
9 & 2156.8 & 2062.1 & 0.84 & 1.52 & 1.72 & 3.4 & $\mathrm{X}$ & $\mathrm{X}$ & 0.95 & 87.79 & 13.95 \\
10 & 2216.5 & 2163.5 & 0.80 & 1.62 & 1.88 & 3.5 & 1.18 & 1.03 & 0.97 & 85.93 & 14.77 \\
11 & 2209.0 & 2060.9 & 0.74 & 2.00 & 2.18 & 4.3 & $\mathrm{X}$ & $\mathrm{X}$ & 0.80 & 64.78 & 13.12 \\
12 & 2180.4 & 2110.6 & 0.76 & 1.43 & 1.74 & 3.3 & 1.33 & 1.17 & 1.12 & 93.45 & 14.77 \\
\hline Mean & 2179.4 & 2065.8 & 0.81 & 1.66 & 1.97 & 3.4 & 1.04 & 0.90 & 0.86 & 80.12 & 14.08 \\
SD & 31.4 & 67.1 & 0.13 & 0.19 & 0.18 & 0.4 & 0.18 & 0.17 & 0.16 & 9.98 & 1.10 \\
\hline
\end{tabular}




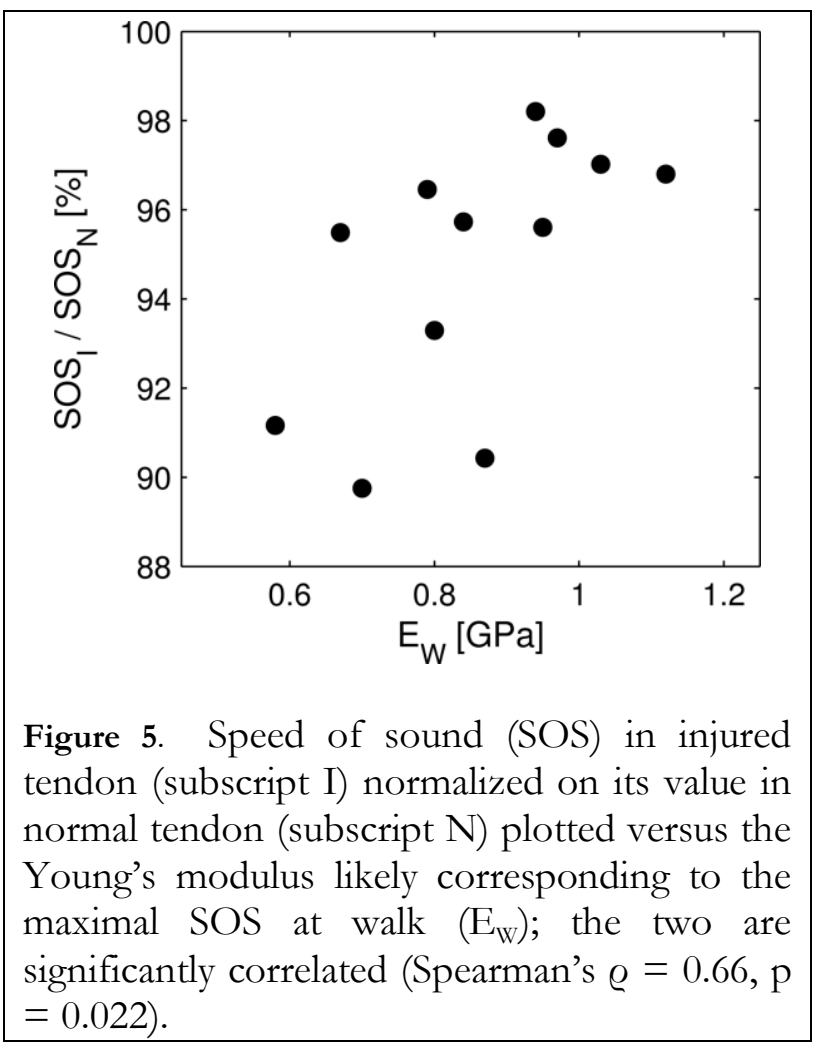

1.0 and 1.6 GPa (Crevier-Denoix et al., 2005; Crevier et al., 1996; Gillis et al., 1995; Riemersma and Schamhardt, 1985), while engineering stress at tendon failure was observed around $125 \mathrm{MPa}$ (Crevier-Denoix et al., 2005; Vergari et al., 2011). Mechanical properties of injured tendons are usually much lower: in tendons suffering from chronic spontaneous lesions, elastic modulus has been observed at $0.74 \pm 0.33 \mathrm{GPa}$ while stress at tendon failure has been found between 53.9 and 63.9 MPa (Crevier-Denoix et al., 1997; CrevierDenoix et al., 2005). The values found in the present study are slightly higher (Table 1), probably because tendons healing from first injuries do not have the same characteristics as tendons affected by chronic tendinitis (CrevierDenoix et al., 2005).

\section{Limitations of the study}

The main limitation of the present study is the lack of a direct correlation between SOS and tendon's elastic modulus, which is probably due to a combination of factors. Axial SOS conveys information on the tissue properties at wavelength scale, but it was compared with elastic moduli which were measured on the whole tendon's cross-section. Tendon can be considered a homogeneous tissue for the propagation of ultrasound at the adopted wavelength; however, this simplified model, which was adopted as a first approximation approach (Eq. 1), probably cannot be applied to injured tendon.

SOS measurements at lower frequency (i.e. larger wavelength) might be more effective in characterizing injured tendon's elastic modulus. Numerical simulations could be utilized, as it was done to characterize ultrasound propagation in cortical bone (Bossy et al., 2002), to understand the wave modes and paths forming the FAS in injured tendons. In particular, the correlation observed between normalized SOS $\left(\mathrm{SOS}_{\mathrm{I}} / \mathrm{SOS}_{\mathrm{N}}\right)$ and tendon's elastic modulus was not predicted by the theory, so it merits to be further investigated. This normalization was tested since it was expected to minimize the initial inter-tendon variability in SOS due to the different tendon loading among horses and tendons' initial mass density and Poisson's ratio. However, more information is needed on the local mechanical and acoustical properties of the injured tissue, which have not yet been characterized.

The peak elastic modulus at walk, $\mathrm{E}_{\mathrm{W}}$, was evaluated by assuming a peak SDFT tendon load, standardised on horse's weight, of $7.3 \pm$ $2.1 \mathrm{~N} / \mathrm{kg}$ (Harrison et al., 2010). The large variability reported in peak load (about $30 \%$ ) does not suffice to explain the lack of correlation between $\mathrm{SOS}_{\mathrm{I}}$ and $\mathrm{E}_{\mathrm{W}}$. Other values of peak tendon load at walk are present in the literature (Butcher et al., 2009; Takahashi et al., 2010), but they give similar results. The limbs' kinematics, which affects tendon's load at walk, was only controlled by standardizing the horses' walk (e.g., horse's speed, head's position, etc.) and was not quantified in the present study, since this type of measure would not be available in current clinical practice.

The comparison of SOS and elastic modulus might also have been affected by the difference between in-vivo and in-vitro determination of the same tendon ROI; $\mathrm{CSA}_{\mathrm{I}}$ was measured in vivo, with the horse standing, in the same region where SOS was measured, while the $\mathrm{CSA}_{\mathrm{E}}$ was 
measured in vitro exactly where the axial strain was being measured. Although significantly different the two areas are strongly correlated, suggesting that the in-vivo and in-vitro regions indeed corresponded, and the CSA difference was mainly due to the tendons being clearly more loaded when $\mathrm{CSA}_{\mathrm{I}}$ was measured. Still, mechanical properties were measured in a 34 $\mathrm{mm}$ tendon segment, while the SOS measures average a $10 \mathrm{~mm}$ segment; while elasticity variations in such a small range are not expected to be large, they can nevertheless play a role in the decrease of correlation between the elastic modulus and SOS.

\section{Conclusions}

Axial SOS was measured in vivo in normal and injured SDFT, observing a significant decrease 3.5 months after injury. A correlation between the normalized SOS values and injured tendon's elastic modulus was found. These results should be now compared with the clinical and ultrasonographic assessment made by clinicians, and confirmed by testing larger samples of tendons. Mass density and Poisson's ratio of injured tendons should be investigated, at different healing stages, and compared to their values in normal tendons in order to assess their impact on tendon SOS. However, these preliminary results confirm the potential of quantitative ultrasound in injured tendons monitoring.

\section{Conflict of interest statement}

The authors have no conflicts of interest to disclose.

\section{Acknowledgments}

The authors are grateful to the Direction Générale de l'Enseignement et de la Recherche (French Ministry of Agriculture), the Région Basse Normandie, the Institut National de la Recherche Agronomique for financial support. We thank Guillaume Gerard and the staff of the equine clinic of the Veterinary school of Alfort for their technical contribution during the experiments.

\section{References}

Bossy, E., Talmant, M., Laugier, P., 2002. Effect of bone cortical thickness on velocity measurements using ultrasonic axial transmission: A 2D simulation study. Journal of the Acoustical Society of America 112, 297-307.

Butcher, M. T., Hermanson, J. W., Ducharme, N. G., Mitchell, L. M., Soderholm, L. V., Bertram, J. E., 2009. Contractile behavior of the forelimb digital flexors during steady-state locomotion in horses (Equus caballus): an initial test of muscle architectural hypotheses about in vivo function. Comparative Biochemistry and Physiology Part A: Molecular \& Integrative Physiology 152, 100-114.

Crevier-Denoix, N., Collobert, C., Pourcelot, P., Denoix, J. M., Sanaa, M., Geiger, D., Bernard, N., Ribot, X., Bortolussi, C., Bousseau, B., 1997. Mechanical properties of pathological equine superficial digital flexor tendons. Equine Veterinary Journal Supplements, 23-26.

Crevier-Denoix, N., Pourcelot, P., Ravary, B., Robin, D., Falala, S., Uzel, S., Grison, A. C., Valette, J. P., Denoix, J. M., Chateau, H., 2009a. Influence of track surface on the equine superficial digital flexor tendon loading in two horses at high speed trot. Equine Veterinary Journal 41, 257-261.

Crevier-Denoix, N., Ravary-Plumioën, B., Evrard, D., Pourcelot, P., 2009b. Reproducibility of a non-invasive ultrasonic technique of tendon force measurement, determined in vitro in equine superficial digital flexor tendons. Journal of Biomechanics 42, 2210-2213.

Crevier-Denoix, N., Ruel, Y., Dardillat, C., Jerbi, H., Sanaa, M., Collobert-Laugier, C., Ribot, X., Denoix, J. M., Pourcelot, P., 2005. Correlations between mean echogenicity and material 
properties of normal and diseased equine superficial digital flexor tendons: an in vitro segmental approach. Journal of Biomechanics 38, 2212-2220.

Crevier, N., Pourcelot, P., Denoix, J. M., Geiger, D., Bortolussi, C., Ribot, X., Sanaa, M., 1996. Segmental variations of in vitro mechanical properties in equine superficial digital flexor tendons. American Journal of Veterinary Research 57, 1111-1117.

Dakin, S. G., Jespers, K., Warner, S., O'hara, L. K., Dudhia, J., Goodship, A. E., Wilson, A. M., Smith, R. K. W., 2011. The relationship between in vivo limb and in vitro tendon mechanics after injury: A potential novel clinical tool for monitoring tendon repair. Equine Veterinary Journal 43, 418-423.

Denoix, J. M., Coudry, V., Seignour, M., Dupays, A. G., Carnicer, D., Audigié, F. (2011) Personal communication.

Denoix, J. M., Mialot, M., Levy, I., Lagadic, M., 1990. Ultrasonography of tendons: histopathological study of lesions correlated with abnormal ultrasonographic findings in the horse tendons and ligaments. Recueil de Medecine Veterinaire 166, 45-55.

Gillis, C., Sharkey, N., Stover, S. M., Pool, R. R., Meagher, D. M., Willits, N., 1995. Effect of maturation and aging on material and ultrsonographic properties of equine superficial digital flexor tendon. American Journal of Veterinary Research 56, 1345-1350.

Gluer, C. C., Blake, G., Lu, Y., Blunt, B. A., Jergas, M., Genant, H. K., 1995. Accurate assessment of precision errors: how to measure the reproducibility of bone densitometry techniques. Osteoporosis International 5, 262-270.

Harrison, S., Whitton, R., Kawcak, C., Stover, S., Pandy, M., 2010. Relationship between muscle forces, joint loading and utilization of elastic strain energy in equine locomotion. The Journal of Experimental Biology 213, 3998-4009.

Laugier, P., Talmant, M., Pham, T. L., 2008. Quo vadis, ultrasonics of bone? Present state and future trends. Archives of Acoustics 33, 553-564.

Marr, C. M., Mcmillan, I., Boyd, J. S., Wright, N. G., Murray, M., 1993. Ultrasonographic and histopathological findings in equine superficial digital flexor tendon injury. Equine Veterinary Journal 25, 23-29.

Moilanen, P., 2008. Ultrasonic guided waves in bone. IEEE Transactions on Ultrasonics, Ferroelectrics, and Frequency Control 55, 1277-1286.

Patterson-Kane, J. C., Firth, E. C., 2009. The pathobiology of exercise-induced superficial digital flexor tendon injury in Thoroughbred racehorses. The Veterinary Journal 181, 79-89.

Pourcelot, P., Defontaine, M., Ravary, B., Lematre, M., Crevier-Denoix, N., 2005. A non-invasive method of tendon force measurement. Journal of Biomechanics 38, 2124-2129.

Rantanen, N. W., Hauser, M. L., Genovese, R. L., 1985. Superficial digital flexor tendinitis; Diagnosis using real-time ultrasound imaging. Journal of Equine Veterinary Science 5, 115119.

Riemersma, D. J., Schamhardt, H. C., 1982. The cryo-jaw, a clamp designed for in vitro rheology studies of horse digital flexor tendons. Journal of Biomechanics 15, 619-620.

Riemersma, D. J., Schamhardt, H. C., 1985. In vitro mechanical properties of equine tendons in relation to cross-sectional area and collagen content. Research in Veterinary Science 39, 263270.

Rose, J. L. 2004. Ultrasonic Waves in Solid Media, Cambridge University Press.

Roux, C., Defontaine, M. 2005. Ultrasonic measurement of the human achilles tendon stress during loading: preliminary experimental and theoretical results. In Ultrasonics Symposium. Rotterdam.

Schramme, M., Hunter, S., Campbell, N., Blikslager, A., Smith, R., 2010. A surgical tendonitis model in horses: technique, clinical, ultrasonographic and histological characterisation. Veterinary and Comparative Orthopaedics and Traumatology 23, 231-239. 
Takahashi, T., Yoshihara, E., Mukai, K., Ohmura, H., Hiraga, A., 2010. Use of an implantable transducer to measure force in the superficial digital flexor tendon in horses at walk, trot and canter on a treadmill. Equine Veterinary Journal 42, 496-501.

Thorpe, C. T., Clegg, P. D., Birch, H. L., 2010. A review of tendon injury: Why is the equine superficial digital flexor tendon most at risk? Equine Veterinary Journal 42, 174-180.

Vergari, C., Pourcelot, P., Holden, L., Ravary-Plumioën, B., Gerard, G., Laugier, P., Mitton, D., Crevier-Denoix, N., 2011. True stress and Poisson's ratio of tendons during loading. Journal of Biomechanics 44, 719-724.

Vergari, C., Pourcelot, P., Holden, L., Ravary-Plumioën, B., Laugier, P., Mitton, D., Crevier-Denoix, N., 2010. A Linear Laser Scanner to Measure Cross-Sectional Shape and Area of Biological Specimens During Mechanical Testing. Journal of Biomechanical Engineering 132, 105001 105008. 